\title{
Contrastivica 2009: Un nuevo foro para la lingǘística contrastiva íbero-germánica
}

\author{
Rál SÁCGEZZ PRiETO \\ Universidad de Salamanca
}

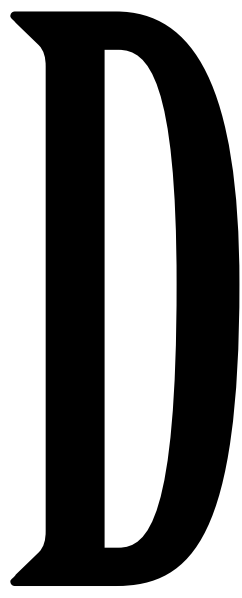

el 12 al 14 de noviembre de 2009 tuvieron lugar en el Aula Magna de la Facultad de Filología de la Universidad de Salamanca los primeros encuentros de lingüística contrastiva española, alemana y portuguesa "Contrastivica 2009». Fueron organizados por los docentes de lingüística del Área de Alemán; la dirección del congreso recayó en Raúl Sánchez Prieto, la presidencia del mismo en Brigitte Eggelte. En el comité organizador estaban también Daniel Veith, Mar Soliño y Nely Iglesias. Durante tres días investigadores universitarios que desarrollan su labor en tres países y que pertenecen a todas las áreas de conocimiento que forman parte de aquello que denominamos lingüística contrastiva expusieron sus últimos trabajos. En los encuentros participaron nueve lingüistas que desarrollan su trabajo en las universidades alemanas del Sarre, Erlangen-Nürnberg, Würzburg, Jena, Bochum, Augsburg y Colonia, 18 germanistas y traductólogos de las universidades españolas de Salamanca, Barcelona, Sevilla, Alicante, Valladolid, Santiago de Compostela, Universidad del País Vasco y Universidad Complutense de Madrid, y 3 germanistas de la afamada Universidad de Coimbra (Portugal).

El objetivo de los encuentros es ofrecer una plataforma de contacto entre romanistas alemanes y germanistas (y traductólogos) españoles y portugueses. La lingüística contrastiva, definida por Kühlwein et al. (1981: 9) como «die Ermittlung der Bedeutung einer Formkategorie in L1 und daraus die Suche nach der Formenpluralität, die L2 für die Realisierung dieser Bedeutung besitzt», vive del intercambio académico de ideas entre las materias de conocimiento que la conforman, y en un contexto germánico y románico los participantes naturales son los germanistas de los países románicos y los romanistas de los países germánicos. Especialmente importante es el papel que desempeña en el ámbito de la enseñanza del alemán como lengua extranjera para hispano- y lusohablantes. En este sentido, y apoyándonos en los únicos dos autores que hasta el momento han publicado una gramática contrastiva de envergadura hispano-alemana, Cartagena/Gauger (1989: VI-VII), podríamos definir como objetivo último de la lingüística contrastiva el facilitar tanto el aprendizaje de la lengua extranjera al alumno, ofreciéndole una relación de estructuras similares o divergentes en su lengua materna y en el idioma que quiere dominar, como la labor explicativa al profesor, poniendo a su disposición un instrumento con el cual discernir usos que sus estudiantes puedan transferir y usos que pueden constituir interferencias lingüísticas.

Teniendo en cuenta este último fin, los participantes en Contrastivica 2009 han contribuido con los trabajos expuestos desde la óptica contrastiva al desarrollo de sus respectivas áreas de conocimiento, enriqueciendo su investigación con las observaciones de los demás ponentes y comunicantes.

\section{Comunicaciones y ponencias presentadas}

Desde el principio Contrastivica 2009 ha querido ser una plataforma de encuentro y discusión, por lo que los organizadores renunciaron al establecimiento de diferentes secciones congresuales. De esta manera, por un lado se limitó en gran medida el número de posibles participantes, pero por otro se evitó la tradicional dispersión de los asistentes en congresos con secciones, que tiene generalmente como consecuencia una escasa presencia de oyentes en ponencias y comunicaciones.

Los ponentes invitados fueron tres. La primera de ellas, la profesora Brigitte Eggelte (Salamanca), expuso su más reciente investigación sobre los verbos prefijados alemanes en contraste con sus equivalentes españoles en «Semantische und syntaktische Leistungen der deutschen Präfixverben im Kontrast zu spanischen Entsprechungen». De gran interés fue el análisis contrastivo-funcional de verbos prefijados por derivación, para los cuales el español muestra diferentes equivalencias entre las que raramente se encuentran verbos prefijados. Su ponencia supone un «novum» dentro de los estudios de gramática contrastiva española y alemana, puesto que la formación verbal y sus implicaciones semánticas y sintácticas apenas han sido investigadas.

La segunda ponente invitada, la profesora Carmen Mellado Blanco (Santiago de Compostela), presentó un estudio fraseológico empírico titulado «Reden ist Silber, Schweigen ist Gold. Metáforas de los campos conceptuales de "hablar mucho" y "callar” en alemán y español». En él analizó los esquemas metafóricos más recurrentes en los campos conceptuales «hablar mucho» y «callar», teniendo como telón de fondo los principios de la semántica cognitiva. Sistematizó los paralelismos y descubrió las divergencias en las imágenes de los dominios fuente de las distintas metáforas analizadas.

La tercera ponente invitada, la profesora Aína Torrent-Lenzen (Colonia/Viena), disertó sobre «las locuciones emotivas en español y su correspondencia al alemán». Tras proponer un marco teórico para el estudio de las emociones y las locuciones emo- 


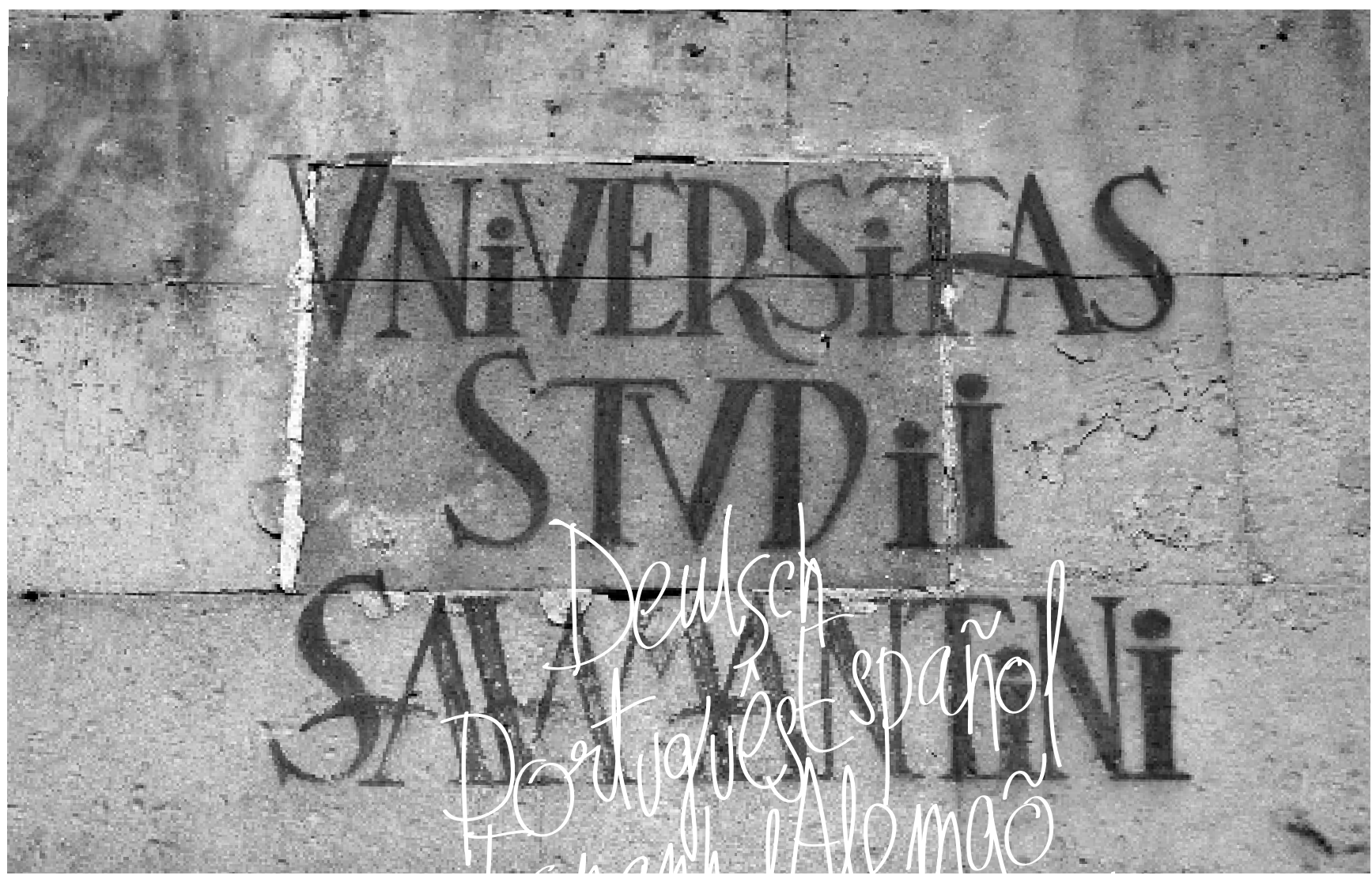

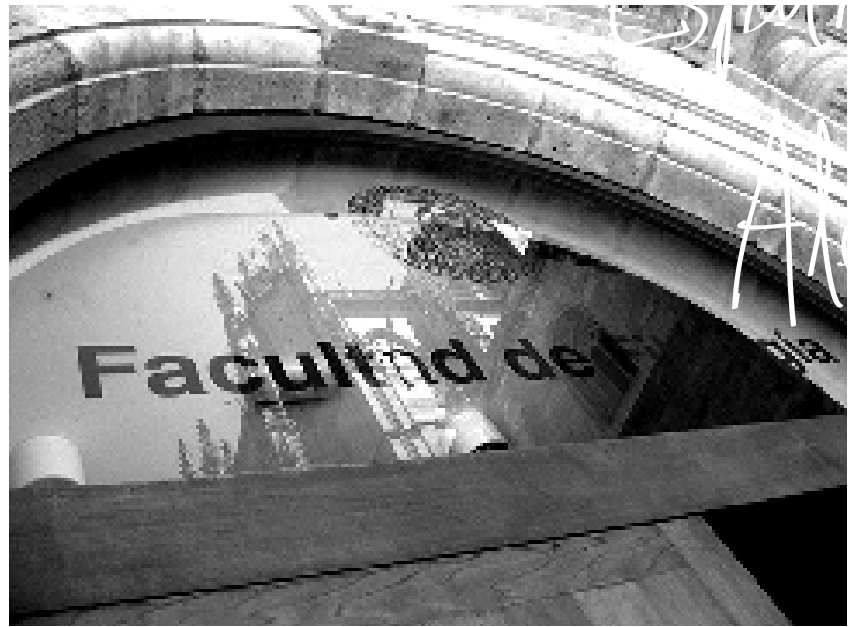

tivas, analizó cómo expresa el alemán las emociones que en español comunicamos mediante el uso de locuciones. Para ello partió de un corpus de ejemplos en su mayoría procedentes de Internet y que formarán parte de un futuro «Diccionario españolalemán de locuciones del español de España».

El resto de comunicaciones se pueden agrupar en torno a cuatro grupos temáticos: gramática contrastiva, fonética y fonología contrastiva, fraseología y lexicografía contrastiva y estudios traductológicos.

Las comunicaciones sobre gramática contrastiva trataron diferentes temas. Ramona Schröpf (Universidad del Sarre) analizó en «Die rhetorischen Dimensionen der Konnektoren in Fernsehinterviews. Eine kontrastive Studie Spanisch - Deutsch» las estra-

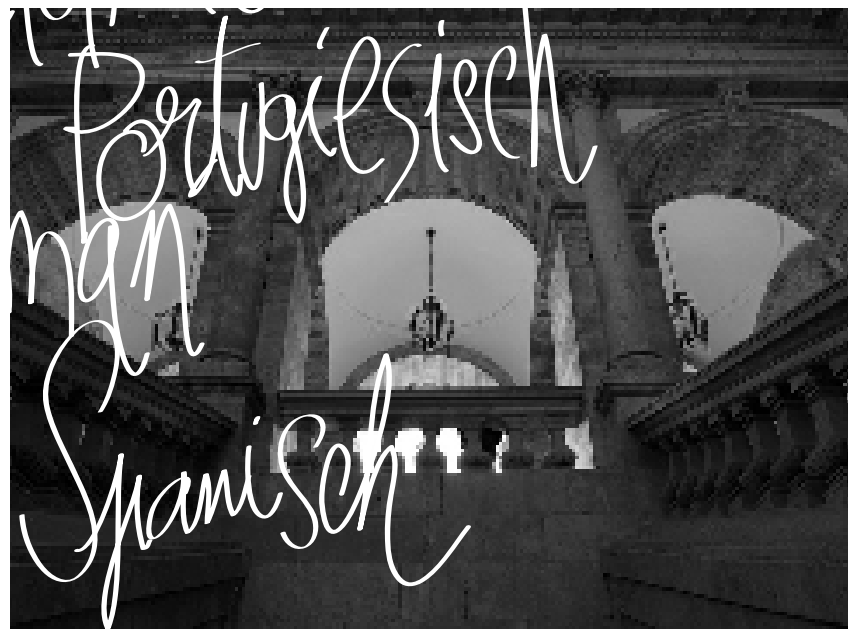

tegias textuales y retóricas que presentan los conectores en español y alemán partiendo de un corpus audiovisual.

María Egido Vicente (Würzburg) expuso en «Las construcciones con verbos funcionales en alemán y español y sus problemas de delimitación» las restricciones morfosintácticas y semánticas que determinan la naturaleza del prototipo de construcción con verbo funcional en español y alemán.

Claudia Grümpel (Alicante) explicó en su comunicación titulada «Die linke und rechte Satzperipherie des Deutschen in Hinblick auf Transferenzfehler im Spracherwerb» los problemas que les supone a los estudiantes hispanohablantes de alemán el fenómeno de coordinación asimétrica del alemán desde la perspectiva de la gramática generativa. 
Raúl Sánchez Prieto (Salamanca) puso en contacto en «Die Präsensformen der am-Periphrase aus deutsch-spanischer kontrastiver Sicht» las formas y usos del presente de indicativo de los paradigmas continuos del español y del alemán. Para ello se basó en un corpus contrastivo recogido a tal efecto.

Carolin Patzelt (Bochum) también se centró en el análisis de las perífrasis verbales españolas. En «Zum Problem einer adäquaten Übersetzung spanischer Verbalperiphrasen ins Deutsche» expuso además las dificultades de su traducción al alemán.

Carmen Castro Moreno (Sevilla) generalizó en «Didáctica aplicada del conjuntivo alemán» sobre diversas cuestiones didácticas referentes al modo conjuntivo alemán.

Daniel Veith (Salamanca) indicó en «Gestern, ich habe viel studiert. Zur Wortstellungsproblematik des Komplexes SubjektFinitum in Deutsch, Spanisch und Portugiesisch» el escaso tratamiento que esta cuestión recibe en los manuales de alemán.

J. Carecho/M. A. Hörster/F. Athayde (Coimbra) analizaron en "Was soll "soll" bedeuten? Os valores do verbo modal alemão "sollen» e a sua expressão em português» la variedad de medios con el que el portugués expresa los usos modales del verbo modal «sollen».

Mar Soliño (Salamanca) presentó en «Lexikalische Variation am Beispiel dynamischer Verben des Deutschen, Spanischen und Portugiesischen» la relación existente entre la variación sintáctica y semántica de verbos dinámicos en alemán, español y portugués.

Mikel Martínez Areta (País Vasco) analizó en «SOV-Ordnung im Baskischen und in den deutschen Nebensätzen» el orden de palabras no marcado SOV en euskera y el marcado SOV en las subordinadas alemanas.

Mireia Calvet Creizet (Barcelona) examinó en «Nomination durch Wortbildung in mehrsprachigen online-Schuhverkaufsseiten» los mecanismos de formación de palabras en el nuevo género digital de publicidad online.

Marta Fernández-Villanueva (Barcelona) analizó en «Kohärenz und Konstruktion narrativer Identität in autobiografischem Erzählen: eine kontrastive Analyse Spanisch-Deutsch» la construcción de la identidad narrativa en textos autobiográficos españoles, catalanes y alemanes desde un punto de vista gramatical.

Sobre fonética y fonología contrastiva disertaron tres participantes. Christian Gebhard (Erlangen-Nürnberg) expuso en «Sprechtempo in Abhängigkeit von Silbenstrukturen» las diferencias en la velocidad de dicción entre el español, el portugués y el alemán.

$\mathrm{M}^{\mathrm{a}}$ Jesús Gil Valdés (Complutense de Madrid) analizó en «La analogía como dificultad en la adquisición de la fonética alemana por estudiantes españoles» los segmentos sonoros alemanes más complicados para los alumnos españoles.

El catedrático Javier Orduña Pizarro (Barcelona) explicó en «Prosodie auf DaF in romanischer Umgebung» las graves diferencias prosódicas que se dan entre el alemán, las demás lenguas románicas e incluso otros grupos de lenguas no indoeuropeas como las silábicas.

Sobre lexicografía y fraseología contrastiva se expusieron diferentes trabajos. Daniel Reimann (Würzburg) examinó concienzudamente en «Kontrastive Pragmatik und transkulturelle kommunikative Kompetenz. Eine Analyse zweisprachiger Lerner- und Handwörterbücher Deutsch-Spanisch/ Spanisch-
Deutsch» las referencias culturales en diccionarios bilingües del español y el alemán.

$M^{a}$ Ángeles Recio Ariza (Salamanca) analizó en «Divergenzen im zweisprachigen Wörterbuch» el tratamiento de la modalidad como factor divergente en algunos diccionarios bilingües español-alemán.

Nely Iglesias Iglesias (Salamanca) describió en «Zweisprachige Phraseografie am Beispiel des Sprachenpaares Deutsch-Spanisch» las equivalencias comunicativo-funcionales de los fraseologismos en diccionarios bilingües español-alemán.

Gilda Cardoso (Augsburg) examinó en «Algumas achegas para o tratamento de verbos alemães formados por prefixação nos dicionários bilingues alemão-português» el tratamiento lexicográfico de los verbos prefijados.

Los estudios de traductología estaban también bien representados. C. Cuéllar/S. Albrecht (Valladolid/ Jena) analizaron en «Comparación lingüística y competencia intercultural: el tratamiento de referencias culturales en el doblaje» las «Realien» en el doblaje.

$\mathrm{M}^{\mathrm{a}}$ Carmen Gómez Pérez (Complutense de Madrid) sometió a debate el papel de la subtitulación y del doblaje en el aprendizaje de lenguas en «El discurso fílmico traducido (alemán-español) y su aprovechamiento en el aprendizaje de idiomas».

Christiane Lebsanft (Complutense de Madrid) examinó en «Funktion und Möglichkeiten der Übersetzung von Partizipialsätzen als Ersatz von adverbialen Nebensätzen in spanischen Gesetzestexten» las posibles traducciones de las construcciones participiales alemanas en textos jurídicos.

Iris Holl (Salamanca) analizó en «Estudio contrastivo del lenguaje jurídico alemán-español: el fallo en la sentencia de divorcio alemana y española» este tipo de textos jurídicos partiendo de un corpus contrastivo.

Andreas Blum (Erlangen-Nürnberg) expuso en «Der Umgang mit dialektal markierten Textpassagen in den spanischen Übersetzungen von Mein Jahrhundert und Im Krebsgang von Günter Grass» las diferentes soluciones que el traductor da a los pasajes dialectales.

\section{Conclusiones.}

Contrastivica 2009 ha sido un útil foro de presentación de las últimas investigaciones sobre lingüística contrastiva española, alemana y portuguesa, en el que se ha ofrecido la oportunidad a sus participantes de entablar contactos con especialistas de disciplinas próximas e igualmente interesadas por el quehacer contrastivo.

Este tipo de encuentros son necesarios en un mundo académico cada vez más interdisciplinar y contrastivo. Habrá que esperar, no obstante, a la publicación de los volumes temáticos del congreso para evaluar su interés entre germanistas, romanistas y traductólogos. De todas formas, la siguiente edición de Contrastiva ya está en camino.

\section{Referencias bibliográficas}

Cartagena, N./Gauger, H.-M. (1989), Vergleichende Grammatik SpanischDeutsch, Mannheim: Duden-Verlag.

Kühlwein, W. et al. (1981), Kontrastive Linguistik und Übersetzungswissenschaft, Múnich: Fink. 